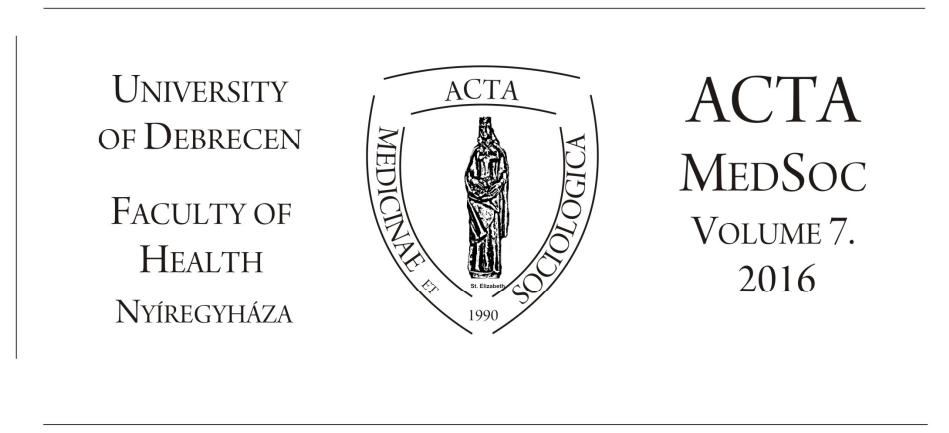

\title{
Pain and its impact on life of rheumatoid arthritis patient
}

\author{
Jiří Kaas, Valérie Tóthová \\ University of South Bohemia in České Budějovice, Faculty of Health and Social \\ Studies, Department of Nursing and Midwifery
}

\begin{abstract}
The goal of the article is to show pain as everyday problem of rheumatoid arthritis patients, to compare its perception from gender perspective and to find relation of pain to other areas of the patient's life. The study was implemented within the research project of the Grant Agency of the University of South Bohemia in České Budějovice number 120/2012/S, ,Reflection of quality of life in nursing", under use of two standardized questionnaires, WHOQOL-100 and HAQ. This article presents exclusively the data acquired based on the WHOQOL-100 questionnaire. The research set consisted of patients suffering from rheumatoid arthritis from all over the Czech Republic. The size of the set was determined by a statistician at 200 individuals suffering from the disease, in a ratio of 150 women and 50 men. The data collection took place from January to May 2013. The statistical data analysis was performed in two stages. The first degree of data sorting was implemented in the SASD program (Statistic Analysis of Social Data); the second degree was implemented in the SPSS program (Statistical Package for the Social Science), version 15.0. The results brought evidence that up to $98,5 \%$ of patients suffer from pain in some form, and that it constitutes an obstacle of different intensity in doing things they need to do for $94,5 \%$ of them. Further, high dependence between facet 1 "pain and discomfort" and facets 9 "mobility" and 2 "energy and fatigue" was demonstrated. Gender-dependent perception does not differ in rheumatoid arthritis patients. The research brought evidence that pain is a very comprehensive problem for rheumatoid arthritis patients. Its impact on other aspects of
\end{abstract}


the patient's life is indisputable, and therefore it should not be dealt with only as physical problem.

Key words: rheumatoid arthritis, pain, patient, rheumatological nursing

DOI: $10.19055 / \mathrm{ams} .2016 .7 / 22-23 / 2$

\section{Introduction}

Rheumatoid arthritis is a globally widespread disease, with current prevalence of 0,5 to $1 \%$ of worldwide population. It is one of the most frequent inflammatory rheumatic diseases, with up to three times higher frequency in women (Luqmani et al 2010; Češka 2010).

Etiologically, it is still a disease with not fully detected causes of origin (Dítě 2007). Pathogenetically, it is a pathological condition with different pathological autoimmune processes in the organism involved in its development and maintenance (Klener 2011).

Clinical picture of rheumatoid arthritis has different intensities; alternation of acute outbursts with periods of remissions of different duration is typical for it. In the first stages, non-specific symptoms usually emerge, e.g. indefinite pains of locomotor system, fatigue, weakness, low performance or increased body temperature. Later, typical joint damage develop under the picture of oligoarthritis or more frequently polyarthritis (DaSilva et al 2010; Adebajo 2010). But as it is a systemic disease, damage of other, so called extra-joint structures like tendons, ligaments, bursae, skin, but also vital organs is possible as well (Pavelka 2010).

In view of the chronic and progressive prognosis of the disease, the therapy is aimed mainly at slowing its course, preventing the development of complications, and thus preserving the highest possible functional level of the patient, both in private and in working life (Pavelková 2009). In recent years, great hopes have been pinned on biological therapy with distinctively positive effects, particularly in the area of physical abilities and physical pain (Olejárová 2010; Závada 2013).

Two of the most frequent and at the same time most uncomfortable symptoms consist in pain and stiffness. Both of those symptoms are related to motor restriction of different intensity (Hill 2006). Rheumatoid arthritis is related to characteristic, so called chronic, non-tumorous pain, typical by its prolonged, usually lifelong course. It is also usually less sensitive to common means applied in pain therapy (Hill 2006; Kolektiv autorů 2006).

The greatest problems related to pain are felt by the rheumatoid arthritis patient usually in the night, at rest, with the greatest intensity in early morning 
hours. When approaching such patient, it is indispensable to view the pain comprehensively and not to perceive it only as physical display, as there is considerable influence of psychosomatics, similarly as in other chronic diseases (Benenson 2011). Psyche plays an important role here particularly due to the fact that the patient faces pain permanently and usually the whole life long (Pavelková 2009). The rheumatoid arthritis patient often gets into a vicious circle, as chronic intensive pain affects negatively the patient's psyche and the disturbed psyche worsens the pain retroactively (Olejárová 2012). Therefore timely diagnostics of the problems and fast start of efficient pain therapy are important, in order to prevent the development of the aforementioned vicious circle (Cush et al 2010).

Stiffness is another prominent problem, emerging very often in rheumatoid patients in connection with pain. It is a symptom constituting reliable indicator of activity of the disease in the rheumatological practice (Hill 2006). Similarly to pain, stiffness is also felt most intensively in early morning hours, with considerable impact on the patient's self-sufficiency in all areas of self-care (Olejárová and Korandová 2011). The cause of morning stiffness consists in inflammation of soft tissues, joint changes and swelling, provoking the feeling of some tightness in the patient (Hill 2006).

Multidisciplinary approach including both pharmacological and nonpharmacological procedures is important in the therapy of both aforementioned symptoms (Cush et al 2010). Rehabilitation plays an essential role here, aimed particularly at supporting the movement, mitigating the pain and eliminating the stiffness (Pavelka 2010). Exercise should constitute a continuous part of the therapy, in order to preserve the highest possible level of the patient's selfsufficiency. Active exercise should be performed regularly by the patient, except for active stages of the disease. But even in those stages, rehabilitation should be continued in form of passive exercise (Olejárová 2008).

Relief from pain and increase of general patient's comfort is the basic task of the nurses working in rheumatology, in order to preserve the highest possible functional level of the patient (Hill 2006). Key roles of the nurse consist in preserving and supporting the highest possible level of the patients self-sufficiency (Olejárová and Korandová 2011). The success is based on approaching pain in as broad context as possible and on dealing with it as early as possible, in order to prevent mental problems from developing due to persisting pain. The nurse has several non-pharmacological options to deal with pain and the related stiffness of the rheumatoid arthritis patient. Application of heat or, on the contrary, cold may be beneficial (Hill 2006); also light exercise preserving muscle strength and supporting mobility is useful (Olejárová and Korandová 2011). When dealing with the stiffness, the most important procedure consists in providing the patient with sufficient time for 
all actions, particularly in morning hours when the feeling of stiffness is most intensive (Hill 2006).

Education is an important part of comprehensive care for rheumatoid arthritis patient (Cush et al 2010), as a sufficiently informed patient copes better with the disease and is therefore more willing to the desirable cooperation (Pavelková 2009). Education must be started as early as possible after the diagnosis. But in the first stages of the disease, it may be less efficient due to the mental strain caused to the patient by the ultimate diagnosis statement. The goal of education consists in giving such amount of information to help the patient to master the new situation as efficiently as possible and to learn to live with it. Well directed education leads to mitigation of fears and prevents different complications from developing (Cush et al 2010).

Physical pain of rheumatoid arthritis patients constitutes a frequently investigated phenomenon in different studies worldwide. Studies demonstrating the impact of pain on the patient's psyche are relatively frequent. For example two studies of American rheumatologists, implemented in Phoenix, Arizona, can be mentioned. The first of them was focused on the relation of pain and emotional health and the second, on the relation of pain and depression in rheumatoid arthritis patients (Sturgeon and Zautra 2013; Zautra et al 2007). Other similar studies include the Turkish study focused on the impact of chronic pain on the psyche of patients with selected rheumatoid diseases, including rheumatoid arthritis (Füsun and Füsun 2002). All aformentioned studies confirmed increased disposition to development of mental problems in connection with chronic pain in rheumatoid arthritis patients (Sturgeon and Zautra 2013; Zautra et al 2007; Füsun and Füsun 2002).

Pain is sometimes researched in such patients also as part of comprehensive quality of life. Specific investigations include the study carried out at the rehabilitation clinic in Novi Sad, Serbia (Tomasevic-Todorovic et al 2011) or the Czech study of quality of life of rheumatoid arthritis patients undergoing biological therapy (Závada et al 2013). Bad quality of life in physical area, particularly in the area of physical pain was found in both studies (TomasevicTodorovic et al 2011; Závada et al 2013). Also the study focused on comparison of comprehensive health, pain intensity and restriction of physical activities performed among American and Swedish population is worth mentioning. The study brought interesting results because it found out that intensity and perception of pain differs between the two nationalities. Based on that fact, the question of individual approach in assessment of pain of rheumatoid arthritis patients with regard to ethnicity and culturality (Björk et al 2011). Last but not least, we can refer to the study performed in South-Eastern Sweden to ascertain the impact of pain on performance of everyday activities by rheumatoid arthritis 
patients. The results brought indisputable evidence of considerable impact of pain on the patient's everyday life (Ahlstrand et al 2012).

\section{Goal}

One of the partial goals of the study was to map the subjectively perceived quality of life in the facet of pain and discomfort. Other goals included finding of the relation of that facet to some selected facets and comparing the subjective perceived quality of life in the facet from gender perspective.

\section{Methodology}

The actual research investigation was carried out with the help of the set of two standardized questionnaires, WHOQOL 100 and HAQ, within research grant project No. 120/2012/S ,Reflection of quality of life in nursing." This article presents only selected results acquired based on the WHOQOL 100 questionnaire. The questionnaire is divided into six domains - physical condition, experiencing, independence, social relations, environment and spirituality, further subdivided into 24 facets. Each of the facets includes four specific questions to be answered by the respondent by choosing one of the answers on a five-degree scale, according to which of the options corresponds the most to the respondent's state in recent fourteen days. The questionnaire includes also four questions focused on general assessment of quality of life and health condition. At the end, the questionnaire includes basic identification data - gender, age, highest education achieved, marital status and current health condition.

The research set consisted of 200 patients suffering from rheumatoid arthritis from all over the Czech Republic. The size of the set was statistically calculated from the basic set of rheumatoid arthritis patients, oscillating between $0,5-0,8$ $\%$ of Czech Population, with approximately three times more frequent incidence in female gender, according to the data stated in recent literature available. Thus the set can be considered representative, with regard to the demographic conditions of the Czech Republic. The actual selection of respondents was carried out based on quota selection; "presence of the diagnosis of rheumatoid arthritis" and "gender" were specified as the sole quotas. The proportion of genders was specified at $75 \%$ women and $25 \%$ men, which also complies with approximate proportion of genders in total Czech population of persons with the disease. Age and region of the respondents was not specified. When creating the 
research set, first of all the organizations providing high incidence of rheumatoid arthritis were approached, namely the Rheumatological institute in Prague and the Rheuma-League Association of the Czech Republic. The data collection took place from January to May 2013. 214 questionnaires were distributed in total, to achieve the required return amount of 200 . The return rate was $93,5 \%$.

The statistical data analysis was performed in two stages. The first degree of classification was performed in SASD program, carrying out calculations of absolute and relative frequencies of obtained answers, as well as calculations of their median values and variability levels. The second degree of classification was performed in SPSS program, version 15.0, including several statistic tests. First, the subjectively perceived quality of life was compared between the set of rheumatoid arthritis patients and the control healthy population, and then it was compared from the perspective of gender and subjectively perceived current health condition. Mann-Whitney $U$ test and non-parametric Wilcox pair test were used for those purposes. Subsequently, Spearman correlation coefficient and determination coefficient were calculated for selected data, in order to find relations for selected facets. The selection of facets for statistical comparison was deliberate; we chose facets in which we had expected some connection and wanted to verify it or disprove it.

\section{Selected results}

In the facet of pain and discomfort, we first ascertained how often the patients suffer from pain, to what degree they are unsettled by the pain, to what degree it is difficult for them to master the pain, and to what degree the pain prevents them from performing things they need to perform.

Based on our research, it was found out that $15 \%$ respondents suffer from pain permanently and 21,5\% "quite frequently". The major part of them used the answer "moderately", with 35,5\% representation. 26,5\% answered to suffer from pain "sometimes", and only 1,5\% "never". In the subsequent question, the respondents answered whether the pain and the related discomfort unsettle them. The answer "moderately" was selected most frequently again, by $45,5 \%$ of the set under research. The answer "a little" ranked second, with frequency of $26 \%$, followed by the opposite option, "a lot", with 20,5\% representation. The answer "not at all" was used by only $6,5 \%$ and the opposite answer, "maximally" by only 1,5 respondents. Further, the respondents were asked to what degree it is difficult for them to master the pain and discomfort. $54 \%$ opted for "moderately" and $27,5 \%$ for "a little". $3 \%$ of the respondents answered not to have any problems with mastering the pain. On the contrary, $15 \%$ chose the 
option "a lot" and one of the respondents (0,5\%) even "maximally". In the last, fourth question, the respondents answered to what degree pain prevents them from doing things they need to do. The major part feels "moderate" restrictions again; such answer was used by $35,5 \%$ of the research set. The answers "a lot" with $29,5 \%$ and "a little" with $27 \%$ ranked second and third. Only a small part $(5,5 \%)$ do not feel any restrictions in this area in connection with pain and chose the answer "not at all". The opposite answer, "maximally", was chosen by 2,5\% respondents.

In performing the second degree of classification, we focused, in connection with the facet of pain and discomfort, on comparing the facet scores between men and women, and further we tried to find the relation of the facet to some other facets.

\begin{tabular}{|c|c|c|c|c|c|}
\cline { 2 - 5 } \multicolumn{1}{c|}{} & \multicolumn{2}{c|}{ Average } & \multicolumn{2}{c|}{ Median } & \multirow{2}{*}{ significance } \\
\cline { 2 - 5 } & $\begin{array}{c}\text { men } \\
(\mathrm{N}=50)\end{array}$ & $\begin{array}{c}\text { women } \\
(\mathrm{N}=150)\end{array}$ & men & women & \\
\hline $\begin{array}{c}\text { Facet } 1 \\
\text { pain and discomfort }\end{array}$ & 11,70 & 11,91 & 12,00 & 12,00 &, 762 \\
\hline
\end{tabular}

Table 1 - Comparison of median values of facet scores from gender perspective in facet 1 pain and discomfort

Table 1 shows comparison of median values of facet scores in the facet of pain and discomfort from gender perspective, performed with the help of MannWhitney $U$ test at the significance level of $p<0,05$. Based on the test performed, no statistically significant differences between men and women were found, thus it can be stated that quality of life in facet 1 pain and discomfort does not differ depending on gender.

\begin{tabular}{|c|l|c|c|c|c|}
\hline \multicolumn{2}{|c|}{ Spearman correlation coefficient } & $\begin{array}{c}\text { Facet 2 } \\
\text { energy } \\
\text { and } \\
\text { fatigue }\end{array}$ & $\begin{array}{c}\text { Facet 3 } \\
\text { sleep } \\
\text { and } \\
\text { rest }\end{array}$ & $\begin{array}{c}\text { Facet 8 } \\
\text { negative } \\
\text { feelings }\end{array}$ & $\begin{array}{c}\text { Facet } 9 \\
\text { mobility }\end{array}$ \\
\hline \multirow{2}{*}{$\begin{array}{c}\text { Facet 1 } \\
\text { pain and } \\
\text { discomfort }\end{array}$} & $\begin{array}{l}\text { Correlation } \\
\text { coefficient }\end{array}$ &,- 777 &,- 545 &, 600 &,- 790 \\
\cline { 2 - 6 } & Sig. (2-tailed) &, 000 &, 000 &, 000 &, 000 \\
\cline { 2 - 6 } & N & 200 & 200 & 200 & 200 \\
\hline \multicolumn{2}{|c|}{ Determination coefficient } & $60 \%$ & $30 \%$ & $36 \%$ & $62 \%$ \\
\hline
\end{tabular}

Table 2 - Relation of facet of pain and discomfort to some selected facets 
Table 2 shows the summarized results of calculations of Spearman correlation coefficient at significance level of $p<0,01$ and of determination coefficient, by which the relations between facet 1 pain and discomfort and four other facets were ascertained. The following facets were chosen: 2 energy and fatigue, 3 sleep and rest, 8 negative feelings and 9 mobility.

High linear dependence of both sizes was found between facet 1 "pain and discomfort" and facet 2 "energy and fatigue"; the determination coefficient is 60 $\%$. High linear dependence was shown also in evaluation of facet 1 with facet 9 "mobility". The determination coefficient between those values was calculated at $62 \%$. When evaluating the relation of facet 1 to facets 3 "sleep and rest" and 8 "negative feelings", moderate linear dependence was proved. The determination coefficient between facets 1 a 3 was calculated at $30 \%$, and between facets 1 and 8 , at $36 \%$.

Based on these results, it can be stated in summary that statistically significant dependence was proved in all relations under research. Thus we can state that patients with higher level of pain feel stronger fatigue, patients with higher level of pain feel more difficulties in the area of sleep and rest, patients with higher level of pain feel more intensive negative feelings and patients with higher level of pain feel more intensive movement problems.

\section{Discussion}

As Hill et al (Hill et al 2006) describe, pain together with stiffness rank among the most frequent and simultaneously most stressing displays of rheumatoid arthritis. Based on our research, it was found out that $98,5 \%$ respondents face pain in different intensities, which is confirmed by its frequent incidence in those patients. Only 1,5\% respondents reported to have pains never. It was also found out that pain constitutes a relatively strong obstacle for the patients in performing things they need to perform. It can be stated in summary that $94,5 \%$ patients perceive pain as an obstacle of different intensity, although $27 \%$ only "a little". But on the other hand, pain constitutes a considerable or even maximal obstacle to almost one third of the set under research (32\%), which we consider a finding worth mentioning. Both questions analyzed above showed most frequently the answer "moderately", which may not seem a serious finding at first sight. But we think that in a chronic disease, faced by the patient for long years or even decades, it is worth mentioning, because it is probable that the patient adapts to the problems somehow in the course of time. During the life with the disease, the patient certainly finds another way of performing some activities, changes his or her daily regime and learns to exist with the help of 
compensation aids, etc.; that is why we think that, in the course of time, the patient may start perceiving some problems, in this case pain, as less serious. This presumption of ours is supported also by the results acquired through other two questions from the facet of pain, in which we ascertained to what degree the pain unsettles the patients and how difficult it is for them to master the pain. The answers in both questions were evaluated as less serious than the answers in the questions focused on how often the patients suffer from the pain or to what degree the pain prevents them from doing things they need to do. That can lead to the conclusion that rheumatoid arthritis patients master pain better than it would correspond to its intensity. This opinion is supported also by Tress et a who report that, in spite of progressive prognosis of the disease, the patients usually master it very patiently (Tress et al 2008). In connection with this, we therefore hold the opinion that our attention should be paid also to problems perceived by the patient as less disturbing at present, because they can actually be considerable problems to which the patient has only adapted to some level. We believe that in such case, even elimination of subjectively less serious problems may distinctively improve the quality of life of the patient.

The subsequent comparison of facet 1 "pain and discomfort", performed from gender perspective, did not bring any surprising conclusions. It was found out that there is no statistically significant difference between how men and women perceive pain, which is in compliance with the conclusions of the study performed at the rehabilitation clinic in Novi Sad, Serbia (TomasevicTodorovic et al 2011).

We consider crucial the data acquired by comparison of facet 1 "pain and discomfort" with other selected facets. The highest level of dependence was proven at evaluating the facet of "pain and discomfort" with the facet "mobility". We consider the finding important particularly because it has brought unmistakable evidence of the fact that movement restriction of such patients does not exist only in itself but that it depends strongly on the level of pain. Predominant part of authors dealing with the issue of rheumatoid arthritis do report that the disease causes movement restrictions of different intensity, nevertheless only a few of them mention pain as a factor contributing to those restrictions. We can state, based on our findings, that if we deal with pain efficiently, we can support significantly the patient's mobility and, therefore, self-sufficiency. High dependence was further proved when performing comparison with facet 2 "energy and fatigue". That relation was interesting for us particularly due to the fact that expert literature often speaks of pain and fatigue as of the most frequent and most restricting problems of rheumatic patients (Hill et al 2008 or Olejárová 2012), but their mutual interaction is mentioned only exceptionally. Other two relations under research (pain - sleep and pain - negative feelings) were evaluated as moderate linear dependence. 
Impact of pain on quality of sleep and rest is logical because, as a lot of authors coincidently describe, inflammatory pain is the most intensive usually in the night, at rest, culminating in early morning hours (Benenson 2011 or Pavelka 2010), and it is therefore not surprising that it does not allow the patient to have quiet and undisturbed sleep. We had expected the impact of pain on the individual's mental aspect, as it is described by a number of authors and proved by relatively numerous studies in this area (Sturgeon and Zautra 2013; Zautra et al 2007; Füsun and Füsun 2002). But we still consider the finding very valuable, as it has brought us evidence of the fact that rheumatoid arthritis is not only physical disease, as frequently regarded, but that there is also quite strong influence of psychosomatics. Benenson tends to this opinion too, considering it indispensable to view pain comprehensively and not to perceive it only as physical symptom (Benenson 2011). Pavelková adds that psyche plays an important role here particularly due to the fact that the patient faces the pain usually for life, and is therefore quite exhausted by the pain (Pavelková 2011). We think that such psychosomatic approach should not be absent even in everyday nursing practice. But it is indispensable for the nurses to become aware of the fact that psychosomatic interaction works in both directions. Mitigation of pain can, on one hand, improve the patient's psyche, but positive influencing of psyche can eliminate the pain as well. The existence of this phenomenon is supported also by Olejárová who describes the development of some vicious circle in mutual influencing of physical area and psyche in case of insufficiently effective and timely therapy of pain (Olejárová 2012). Comprehensive approach in therapy of rheumatoid arthritis, including the patient's psyche, is emphasized also in the study of Zautra et al who describe the importance of suggesting cognitively behavioral approaches as integral part of comprehensive therapy of rheumatoid arthritis (Zautra et al 2007).

If looking at all results in summary, it is evident that pain is really an extensive problem of rheumatoid arthritis patients, with negative impact on a lot of other aspects of the patient. Thus it can be assumed that if pain is dealt with really holistically and, first of all, in time, it will have positive influence in the area of sleep and rest, improve the patient's general mobility, mitigate mental symptoms and reduce general fatigue and exhaustion. In our opinion, it is also probable that improved sleep will further mitigate the feeling of fatigue, which can be further reflected in the patient's psyche, which will mitigate even more the primary pain. The improvement in the area of movement will certainly bring a lot of good results as well. Based on these findings, we think that pain should be dealt with really comprehensively, with all its causes and consequences, and that pharmacotherapy should not constitute the only therapeutic procedure applied in its mastering. We also favour the importance of multidisciplinary 
approach in dealing with pain in rheumatoid arthritis patients, supported by Cush et al (Cush et al 2010).

\section{Conclusion}

As described above, pain ranks among rheumatoid arthritis symptoms that exhaust the patient considerably. The results of our study confirmed its negative relation to further, essential areas of the patient's life, which is the most intensive in the area of movement. When providing nursing care to rheumatoid arthritis patients, it is important to understand that movement is an ability that makes a person free, independent and first of all self-sufficient. Any disruption of this area will very probably affect also other dimensions of the person. The nurse has a lot of non-pharmacological procedures available to mitigate pain and therefore influence positively also other areas. As our study has shown, if pain is efficiently monitored and dealt with in time, it can very probably bring improvements in the area of sleep and rest, energy and fatigue, mobility and last but not least in the area of psyche. But it is also important that pain can be positively influenced also retroactively, by positive actions upon the patient's psyche or the area of sleep. Thus we can state that the base for successful care for the rheumatoid arthritis patient consists in holistic approach and in getting rid of viewing rheumatoid arthritis as purely physical disease.

\section{References}

1. Adebajo, A., 2010. ABC of Rheumatology. 4th ed. Chichester: WileyBlackwell. ISBN 978-1-40-51-7068-0.

2. Ahlstrand, I. et al., 2012. Pain and daily activities in rheumatoid arthritis. Disability and Rehabilitation. 34(15), 1245-1253. ISSN 0963-8288.

3. Benenson, E., 2011. Rheumatology: Symptoms and Syndromes. London: Springer. ISBN 978-1-84996-461-6.

4. Björk, M. et al., 2011. Differences in activity limitation, pain intensity, and global health in patients with rheumatoid arthritis in Sweden and the USA: a 5-year follow-up. Scandinavian Journal of Rheumatology. 40, 428-432. ISSN 0300-9742.

5. Cush, J. J., M. E. Weinblatt and A. Kavanaugh, 2010. Rheumatoid Arthritis: Early Diagnosis and Treatment. 3rd ed. New York: Professional Communications, Inc. ISBN 978-1-932610-58-1.

6. Češka, R. et al., 2010. Interna. Praha: Triton. ISBN 978-80-7387-423-0. 
7. Da Silva, J. A. P and A. D. Woolf, 2010. Rheumatology in Practice. London: Springer. ISBN 978-1-84882-580-2.

8. Dítě, P., 2007. Vnitřní lékařství. 2nd ed. Praha: Galén. ISBN 978-80-7262496-6.

9. Füsun, A. and T. FÜSUN, 2002. Psychological Dimensions of Pain in Patients with Rheumatoid Arthritis, Fibromyalgia Syndrome and Chronic Low Back Pain. Journal of Musculoskeletal Pain. 10(4), 19-29. ISSN 1058-2452.

10. Hill, J. et al., 2006. Rheumatology nursing: a creative approach. 2nd ed. Chichester: John Wiley and Sons, Ltd. ISBN 978-0-470-01961-0.

11. Klener, P., 2011. Vnitřní lékařství. 4th ed. Praha: Galén. ISBN 978-807262-705-9.

12. Kolektiv Autorů, 2006. Vše o léčbě bolesti. Praha: Grada. ISBN 80-247$1720-4$.

13. Luqmani, R., T. Pincus and M. Boers, 2010. Rheumatoid Arthritis. Oxford: Oxford University Press. ISBN 978-0-19-955675-5.

14. Olejárová, M., 2010. Biologická léčba v revmatologii. Praha: Mladá fronta. ISBN 978-80-204-2281-1.

15. Olejárová, M., 2012. Revmatoidní artritida: čtení o nemoci severoamerických indiánů, slavných malírũ i vaší. Praha: Mladá fronta. ISBN 978-80-204-2657-4.

16. Olejárová, M., 2008. Revmatologie v kostce. Praha: Triton. ISBN 978-807387-115-4.

17. Olejárová, M. and J. Korandová, 2011. Lexikon revmatologie pro sestry. Praha: Mladá fronta. ISBN 978-80-204-2455-6.

18. Pavelka, K., 2010. Revmatologie. 2nd ed. Praha: Galén. ISBN 978-807262-688-5.

19. Pavelková, A., 2009. Revmatoidní artritida a biologická léčba. Praha: Maxdorf. ISBN 978-80-7345-192-9.

20. Sturgeon, J. A. and A. J. Zautra, 2013. State and Trait Pain Catastrophizing and Emotional Health in Rheumatoid Arthritis. Annals of Behavioral Medicine. 45, 69-77. ISSN 0883-6612.

21. Tomasevic-Todorovic, S. et al., 2011. Assessment of life quality in patients with Rheumatoid Arthritis. HealthMED Journal. 5(6), 2190-2195. ISSN 1840-2291.

22. Tress, W., J. Krusse and J. OTT, 2008. Základní psychosomatická péče: Praha: Portál. ISBN 978-80-7367-309-3.

23. Zautra, A. J. et al., 2007. Depression History, Stress, and Pain in Rheumatoid Arthritis Patients. Journal of Behavioral Medicine. 30, 187197. ISSN 0160-7715. 
24. Závada, J. et al., 2013. Zdravím podmíněná kvalita života u pacientů s revmatoidní artritidou $\mathrm{v}$ průběhu prvního roku anti-TNF léčby. Česká Revmatologie. 21(3), 123-130. ISSN 1210-7905.

The article is related to the research grant project number 120/2012/S, implemented under financial support of the Grant Agency of the Faculty of Health and Social Studies in České Budějovice.

Jiří Kaas, Mgr., RN

$\mathrm{PhD}$ student

University of South Bohemia in České Budějovice, Faculty of Health and Social Studies, Department of Nursing and Midwifery, Czech Republic

U Výstaviště 26, 37005 České Budějovice

e-mail address: mike1777@seznam.cz

phone number: +420389037518

Valérie Tóthová, prof., PhDr., PhD., RN

Dean of Faculty of Health and social Studies of University of South Bohemia in České Budějovice, Czech Republic

Jírovcova 1347/24, 37004 České Budějovice

e-mail address: tothova@zsf.jcu.cz

phone number: +420389037500 
